\title{
Green synthesis of magnetic chitosan nanocomposites by a new sol-gel auto-combustion
}

\section{method}

\author{
Fatemeh Ansaria ${ }^{\mathrm{a}}$ Azam Sobhani ${ }^{\mathrm{b}}$, Masoud Salavati-Niasari*a \\ ${ }^{a}$ Institute of Nano Science and Nano Technology, University of Kashan, Kashan, P. O. Box. 87317-51167, I. R. Iran. \\ ${ }^{b}$ Department of Chemistry, Kosar University of Bojnord, Bojnord, Islamic Republic of Iran.
}

*Correspondence address: Tel.: +98 315591 2383; Fax: +98 31 55913201. E-mail address: salavati@kashanu.ac.ir.

\begin{abstract}
The $\mathrm{Fe}_{2} \mathrm{O}_{3} / \mathrm{CuFe}_{2} \mathrm{O}_{4} /$ chitosan nanocomposites have been successfully synthesized via a new sol-gel autocombustion route. To prepare the nanocomposites, copper ferrite $\left(\mathrm{CuFe}_{2} \mathrm{O}_{4}\right)$ and iron (II) oxide (Fe $\left.\mathrm{O}_{3}\right)$ nanostructures were first prepared utilizing onion as a green reductant for the first time, and characterized by SEM, TEM, XRD, IR and VSM. Then chitosan was added into the nanostructures dispersed in water. Chitosan was used to functionalize and modify the nanostructures and also to improve surface properties. The nanocomposites were also characterized by several techniques including SEM, TEM, XRD, IR and VSM. The effects of amount of onion and chitosan on the morphology and particle size of nanocomposites were evaluated.
\end{abstract}

Keywords: Nanocomposites; Chitosan; Sol-gel; Auto-combustion process; Copper ferrite; Magnetic properties.

\section{Introduction}

Chitosan is a low-cost and effective adsorbent compared with activated carbons and other adsorbents used in treatment organic or inorganic contaminated water $[1,2]$. In recent years, extensive attention has been paid to the performance of chitosan as an adsorbent for pollutants from water $[3,4]$. This is due to the unique polycationic structure, selectivity and cationic behavior of chitosan. Chitosan, as a natural polysaccharide, has reactive amino and hydroxyl groups in its linear polyglucosamine chains that can be used to functionalize and modify ferrite nanoparticles $[5,6]$. In general, chitosan itself does not exhibit magnetic properties. With adding a magnetic 
component to chitosan, including $\mathrm{Fe}_{3} \mathrm{O}_{4}, \mathrm{Fe}_{2} \mathrm{O}_{3}, \mathrm{NiFe}_{2} \mathrm{O}_{4}, \mathrm{CoFe}_{2} \mathrm{O}_{4}, \mathrm{CuFe}_{2} \mathrm{O}_{4}$ and $\mathrm{ZnFe}_{2} \mathrm{O}_{4}$, the magnetic nanocomposites are obtained [6-9]. Magnetic chitosan composites have a fast adsorption rate and high adsorption efficiency, efficient to remove various pollutants and they are easy to recover and reuse. Significant interests have been generated in preparing magnetic chitosan nanocomposites for their exceptional electromagnetic properties in many applications ranging from metal ions adsorption to drug delivery $[10,11]$.

It is well known that properties of powders depend on their particle size and morphology [12-16]. Therefore, exploring appropriate methods to synthesize nanomaterials and controlling their particle morphology and size is crucially important. Herein, we develop the sol-gel auto-combustion route to prepare $\mathrm{CuFe}_{2} \mathrm{O}_{4}$ and $\mathrm{Fe}_{2} \mathrm{O}_{3}$ nanostructures. This is a novel way with a unique combination of the chemical sol-gel process and the autocombustion process based on the gelling and subsequent auto-combustion [17]. Then the nanostructures are coated with the chitosan to improve surface properties and enhance loading capacity when used in magnetic targeted delivery and metal ions adsorption [18]. This approach is simple, low-cost and friendly to the environment. We have used nontoxic reactants and solvent. Water is an interminable, cheap, available solvent. At the first time, we have used onion as reductant for green synthesis of magnetic nanocomposites and also it is the first time that $\mathrm{Fe}_{2} \mathrm{O}_{3} / \mathrm{CuFe}_{2} \mathrm{O}_{4} /$ chitosan nanocomposites are synthesized. Onion contains vitamin $\mathrm{C}$ as one of its constituents. The vitamin $\mathrm{C}$ is responsible for the reduction.

\section{Experimental}

\subsection{Materials and experiments}

All the chemicals used in our experiments were of analytical grade, were purchased from Merck and used as received without further purification. XRD patterns were collected from a diffractometer of Philips Company with X'PertPro monochromatized $\mathrm{Cu}$ K $\alpha$ radiation $(\lambda=1.54 \AA$ A). FE-SEM images were obtained on MIRA3 FEG-SEM. TEM images were obtained on a Philips EM208S transmission electron microscope with an accelerating voltage of 100 kV. FT-IR spectrum was recorded with Shimadzu Varian 4300 spectrophotometer in KBr pellets. The magnetic 
properties of the samples were detected at room temperature using a vibrating sample magnetometer (VSM, Meghnatis Kavir Kashan Co., Kashan, Iran).

\subsection{Synthesis of $\mathrm{Fe}_{2} \mathrm{O}_{3}$ and $\mathrm{CuFe}_{2} \mathrm{O}_{4}$}

$\mathrm{Fe}_{2} \mathrm{O}_{3}$ and $\mathrm{CuFe}_{2} \mathrm{O}_{4}$ nanostructures were prepared by the sol-gel auto-combustion process. First, $\mathrm{Cu}\left(\mathrm{NO}_{3}\right)_{2}$ was dissolved in distilled water to form a clear solution. Then an aqueous solution containing onion was added into the copper nitrate solution drop-wise under strong magnetic stirring at room temperature. The onion aqueous was prepared by finely cutting onion and then taking its water. The experiments were carried out with three different amounts of onion that including 0,20 and $40 \mathrm{ml}$. The solution was heated by stirring at $60{ }^{\circ} \mathrm{C}$. After stirring the solution for 30 min, an aqueous solution containing $\mathrm{Fe}\left(\mathrm{NO}_{3}\right)_{3} .9 \mathrm{H}_{2} \mathrm{O}$ was added to the above solution and was heated at $120{ }^{\circ} \mathrm{C}$ by stirring for $1 \mathrm{~h}$. Evaporation of the mixed solution caused formation of a highly viscous gel. The gel then was dried in an oven at $100{ }^{\circ} \mathrm{C}$. The final residue was calcined at $900{ }^{\circ} \mathrm{C}$ for $3 \mathrm{~h}$ to form the $\mathrm{Fe}_{2} \mathrm{O}_{3}$ and $\mathrm{CuFe}_{2} \mathrm{O}_{4}$ nanostructures.

\subsection{Synthesis of $\mathrm{Fe}_{2} \mathrm{O}_{3} / \mathrm{CuFe}_{2} \mathrm{O}_{4} /$ chitosan nanocomposites}

To prepare the $\mathrm{Fe}_{2} \mathrm{O}_{3} / \mathrm{CuFe}_{2} \mathrm{O}_{4} /$ chitosan nanocomposites, chitosan was dissolved in distilled water and acetic acid. The molecular weight of chitosan used was 100000-300000 and the volume ratio of water and acid used was 10:1. Then $\mathrm{Fe}_{2} \mathrm{O}_{3}$ and $\mathrm{CuFe}_{2} \mathrm{O}_{4}$ nanostructures dispersed in distilled water, were added into the solution under strong magnetic stirring. The mixture was stirred for $24 \mathrm{~h}$ until the water was vapored. The nanocomposites were washed with distilled water and ethanol several times, and dried under vacuum at $60{ }^{\circ} \mathrm{C}$ for $4 \mathrm{~h}$. Table 1 lists the reaction terms for the synthesis of the products in this work.

\section{Results and discussion}

To investigate the effect of different parameters on the morphology and particle size of the products, the various experiments were performed. All of the preparation terms have been illustrated in Table 1. It is suggested that the following reactions occur during the calcination process. The $\mathrm{Fe}\left(\mathrm{NO}_{3}\right)_{3}$ and $\mathrm{Cu}\left(\mathrm{NO}_{3}\right)_{2}$ salts are decomposed (Eqs. 1 
and 2). Reaction of the $\mathrm{Fe}_{2} \mathrm{O}_{3}$ with the $\mathrm{CuO}$ is caused to formation of $\mathrm{CuFe}_{2} \mathrm{O}_{4}$ (Eq. 3). The $\mathrm{CuFe}_{2} \mathrm{O}_{4}, \mathrm{Fe}_{2} \mathrm{O}_{3}$ and chitosan are combined together to form the $\mathrm{Fe}_{2} \mathrm{O}_{3} / \mathrm{CuFe}_{2} \mathrm{O}_{4} /$ chitosan nanocomposites (Eq. 4):

$2 \mathrm{Fe}\left(\mathrm{NO}_{3}\right)_{3} \rightarrow \mathrm{Fe}_{2} \mathrm{O}_{3}+\mathrm{NO}_{\mathrm{x}} \ldots \ldots \ldots \ldots \ldots \ldots \ldots \ldots \ldots \ldots \ldots \ldots$

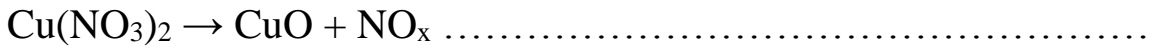

$\mathrm{CuO}+\mathrm{Fe}_{2} \mathrm{O}_{3} \rightarrow \mathrm{CuFe}_{2} \mathrm{O}_{4} \ldots \ldots \ldots \ldots \ldots \ldots \ldots \ldots \ldots \ldots \ldots \ldots \ldots$

$\mathrm{Fe}_{2} \mathrm{O}_{3}+\mathrm{CuFe}_{2} \mathrm{O}_{4}+$ chitosan $\rightarrow \mathrm{Fe}_{2} \mathrm{O}_{3} / \mathrm{CuFe}_{2} \mathrm{O}_{4} /$ chitosan $\ldots \ldots \ldots \ldots$.

The morphologies of the obtained nanostructures and corresponded nanocomposites were investigated by SEM and TEM. Fig. 1 shows SEM images of samples no. 1, 2 and 3. Fig. 1a and b show that coalesced particles and bulk structures were obtained in the absence of onion. Whereas, in case of samples obtained in the presence of $20 \mathrm{ml}$ (sample no. 2, Fig. 1c, d) and $40 \mathrm{ml}$ onion (sample no. 3, Fig. 1e, f), irregular prisms and layer hexagonal plates are formed, respectively. The SEM images in Fig. 1c-f clearly show that the surface of the prisms and plates are not smooth and have been covered with nanoparticles with a diameter lower than $10 \mathrm{~nm}$. The SEM images reveal that, in our experimental conditions, the ideal amount of the onion for the synthesis of $\mathrm{Fe}_{2} \mathrm{O}_{3}$ and $\mathrm{CuFe}_{2} \mathrm{O}_{4}$ nanostructures is $40 \mathrm{ml}$.

Fig. 2a-f shows the SEM images of nanocomposites prepared in the presence of $40 \mathrm{ml}$ onion, with different amounts of chitosan involving $0.5,1,2,5,10$ and $50 \% \mathrm{~W} / \mathrm{W}$, respectively. According to the SEM images, it is found that the morphology and crystallinity of the nanocomposites depend on the amount of the chitosan. When the amount of chitosan is low $(0.5,1$ and $2 \% \mathrm{~W} / \mathrm{W})$, spherical nanoparticles with nearly even size distribution are formed, as shown in Fig. 2a-c. With increasing the amount of chitosan from 0.5 to 1 and then $2 \% \mathrm{~W} / \mathrm{W}$, the size of the nanoparticles were increased and their agglomeration were decreased. With increasing amount of the chitosan to $5 \% \mathrm{~W} / \mathrm{W}$, rectangular structures are formed, the directional linkage of the rectangles is observed in Fig. $2 \mathrm{~d}$. In sample no. 8 obtained in the presence of $10 \%$ chitosan, aggregated structures are formed. Whereas, in case of sample no. 9 which was obtained in the presence of $50 \%$ chitosan, agglomerated nanoparticles are formed. 
Fig. 3 shows TEM images of two samples obtained in the presence of $40 \mathrm{ml}$ onion, one without (sample no. 3) and the other with $1 \%$ chitosan (sample no. 5). The TEM images reveal that spherical nanoparticles are formed in both samples. The nanoparticles in Fig. 3a have nearly even size distribution with an average size of $\sim 5 \mathrm{~nm}$. These nanoparticles have been formed on surfaces of hexagonal plates, as shown in Fig. 1e and f. TEM images of the nanocomposites obtained in the presence of $1 \%$ chitosan (Fig. 3b, c) show formation of nanoparticles with size of $5-45 \mathrm{~nm}$.

In other side, the crystal structure and composition of the as-prepared samples were determined by XRD. Fig. 4a and $b$ shows the XRD patterns of the samples no. 3 and 5, respectively. The product obtained in the presence of 40 $\mathrm{ml}$ onion and without chitosan (sample no. 3) is a mixture of $\mathrm{CuFe}_{2} \mathrm{O}_{4}$ and $\mathrm{Fe}_{2} \mathrm{O}_{3}$ (Fig. 4a). The peaks which have been indexed with green (or star) and blue colors in Fig. 4a indicate the $\mathrm{Fe}_{2} \mathrm{O}_{3}$ and $\mathrm{CuFe}_{2} \mathrm{O}_{4}$, respectively. Five characteristic peaks for $\mathrm{Fe}_{2} \mathrm{O}_{3}$ marked by their indices ((111), (220), (311), (222) and (440)) are observed in Fig. 4a. These peaks are consistent with the database in JCPDS card No. 84-0307 and reveal $\mathrm{Fe}_{2} \mathrm{O}_{3}$ with a rhombohedral phase. The other peaks indexed with blue color indicate the cubic phase of $\mathrm{CuFe}_{2} \mathrm{O}_{4}$ (JCPDS card No. 25-0283) and correspond to diffractions from the (012), (104), (110), (113), (202), (024), (116), (018), (214) and (300) planes. XRD studies show that raw chitosan itself is amorphous in nature [19], but magnetic chitosan exhibits crystallinity due to the presence of iron oxide particles. XRD pattern of $\mathrm{Fe}_{2} \mathrm{O}_{3} / \mathrm{CuFe}_{2} \mathrm{O}_{4} /$ chitosan nanocomposite in Fig.4b reveals that the chitosan coating do not result in the phase change of $\mathrm{Fe}_{2} \mathrm{O}_{3}$ and $\mathrm{CuFe}_{2} \mathrm{O}_{4}$. The diffraction peaks for $\mathrm{Fe}_{2} \mathrm{O}_{3}$ and $\mathrm{CuFe}_{2} \mathrm{O}_{4}$ nanostructures are observed at lower 2(theta) positions after the formation of the nanocomposites. The XRD results show that the nanostructures are really encapsulated with the chitosan.

Fig. 5a and $b$ shows FT-IR spectra for the $\mathrm{Fe}_{2} \mathrm{O}_{3} / \mathrm{CuFe}_{2} \mathrm{O}_{4}$ nanostructures (sample no. 3) and $\mathrm{Fe}_{2} \mathrm{O}_{3} / \mathrm{CuFe}_{2} \mathrm{O}_{4} /$ chitosan nanocomposites (sample no. 5), respectively. FT-IR spectroscopy is one of the most important and widely used analytical methods for obtaining information about the availability of certain functional groups in the structure of the magnetic nanocomposites. In FT-IR spectrum of sample no. 3 (Fig. $5 a$ ), the absorption 
band at $3429 \mathrm{~cm}^{-1}$ is attributed to the $\mathrm{O}-\mathrm{H}$ stretching of water. The band corresponding to the bending vibrations of $\mathrm{H}_{2} \mathrm{O}$ molecules is positioned at $1629 \mathrm{~cm}^{-1}$. The peak at $576 \mathrm{~cm}^{-1}$ relates to the metal-O stretching vibration. Most studies have shown that chitosan exhibits the following peaks: $\sim 3436 \mathrm{~cm}^{-1}$ due to $\mathrm{O}-\mathrm{H}$ and $\mathrm{N}-\mathrm{H}$ stretching vibrations, $\sim 1550 \mathrm{~cm}^{-1}$ due to $\mathrm{NH}_{2}$ bending vibration, and $\sim 1382,1083$ and $1023 \mathrm{~cm}^{-1}$ due to $\mathrm{C}-\mathrm{O}$ stretching vibrations $[6,20]$. The interactions between ferrites and the polysaccharide type biopolymers are proved by FTIR. Some interactions between ferrite, iron oxide and chitosan can be explained by the shifting to higher values of the bands assigned to $v_{\mathrm{OH}} / \mathrm{NH}$ and $\delta_{\mathrm{NH} 2}$ from $3439 \mathrm{~cm}^{-1}$ and $1571 \mathrm{~cm}^{-1}$ in the spectrum of $\mathrm{Fe}_{2} \mathrm{O}_{3} / \mathrm{CuFe}_{2} \mathrm{O}_{4} / \mathrm{chitosan}$ than the corresponding ones in chitosan spectrum (3436 and $1550 \mathrm{~cm}^{-1}$ ), respectively. Moreover, the characteristic adsorption bands appear at 1409, 1102 and $1024 \mathrm{~cm}^{-1}$ which can be assigned to $\mathrm{C}-\mathrm{O}$ group, and a sharp peak at 615 $\mathrm{cm}^{-1}$ related to metal-O group appears. Overall, the FT-IR spectrum provides supportive evidence that the surface of $\mathrm{Fe}_{2} \mathrm{O}_{3} / \mathrm{CuFe}_{2} \mathrm{O}_{4}$ nanostructures are successfully coated with chitosan chains.

Fig. 6 shows plots of magnetization versus applied field (M-H) for the $\mathrm{Fe}_{2} \mathrm{O}_{3} / \mathrm{CuFe}_{2} \mathrm{O}_{4}$ nanostructures (sample no. 3) and $\mathrm{Fe}_{2} \mathrm{O}_{3} / \mathrm{CuFe}_{2} \mathrm{O}_{4} /$ chitosan nanocomposites (sample no. 5) at $300 \mathrm{~K}$. The plots show ferromagnetic behavior for both samples. Ferromagnets (permanent magnets) can retain a memory of an applied field once it is removed, this behavior is called hysteresis. Hystersis loop illustrates the technical magnetic properties of a ferromagnetic material [21-24]. It can be seen that the saturation magnetization of the nanocomposites is about $9.65 \mathrm{emu} / \mathrm{g}$, which is lower than the value of corresponding $\mathrm{Fe}_{2} \mathrm{O}_{3} / \mathrm{CuFe}_{2} \mathrm{O}_{4}$ nanostrutures $(12.06 \mathrm{emu} / \mathrm{g}$ ) and it may be most likely due to the existence of chitosan coating layer. In addition, the coercivity decrease can further prove that chitosan has successfully coated onto the surface of the nanostructures. It may be explained by the fact that the coercivity can be affected by surface anisotropy, which would be sensitive to surface modification [25]. Because the surface anisotropy is known to decrease upon coating, a smaller coercivity is obtained with the formation of chitosan coating layer on the $\mathrm{Fe}_{2} \mathrm{O}_{3} / \mathrm{CuFe}_{2} \mathrm{O}_{4}$ nanoparticles. The magnetic hysteresis parameters of two samples no. 3 and 5 have been compared in Table 2. 
The $\alpha-\mathrm{Fe}_{2} \mathrm{O}_{3}$ has $\mathrm{M}_{\mathrm{s}}=3.7 \mathrm{emu} / \mathrm{g}$ and $\mathrm{H}_{\mathrm{c}}=39$ Oe that are lower from nanocomposites synthesized in this work [26]. The $\mathrm{M}_{\mathrm{s}}$ of $\mathrm{CoFe}_{2} \mathrm{O}_{4} / \mathrm{DTPA}$-chitosan nanocomposites is about $26.6 \mathrm{emug}^{-1}$, which is higher than the value of corresponding $\mathrm{CuFe}_{12} \mathrm{O}_{19} /$ chitosan nanocomposite obtained in this work, $9.49 \mathrm{emug}^{-1}$ [27].

\section{Conclusions}

This study reports a two-steps route for obtaining magnetic nanocomposites consisting of $\mathrm{Fe}_{2} \mathrm{O}_{3}, \mathrm{CuFe}_{2} \mathrm{O}_{4}$ and chitosan by sol-gel auto-combustion route. The nanocomposites show feromagnetic behavior. The effects of onion and chitosan amount on the morphology and particle size of nanocomposites are investigated. To the best of our knowledge, it is the first time that $\mathrm{Fe}_{2} \mathrm{O}_{3} / \mathrm{CuFe}_{2} \mathrm{O}_{4} /$ chitosan nanocomposites are synthesized and also it is the first time that onion, as reductant, and sol-gel auto-combustion route are used for the synthesis of these nanocomposites. The method is proved to be a new, simple, efficient and quick way.

\section{Acknowledgment}

Authors are grateful to the council of Iran National Science Foundation (91053846) and University of Kashan for supporting this work by Grant No (159271/379). 


\section{References}

[1] Bhatnagar A, Sillanpää M. Applications of chitin- and chitosan-derivatives for the detoxification of water and wastewater-A short review. Adv Colloid Interface Sci 2009;152:26-38.

[2] Crini G, Badot P-M. Application of chitosan, a natural aminopolysaccharide, for dye removal from aqueous solutions by adsorption processes using batch studies: a review of recent literature. Prog Polym Sci 2008;33:399447.

[3] Miretzky P, Cirelli AF. Fluoride removal from water by chitosan derivatives and composites: a review. J Fluor Chem 2011;132:231-40.

[4] Elwakeel KZ. Environmental application of chitosan resins for the treatment of water and wastewater: a review. J Dispersion Sci Technol 2010;31:273-88.

[5] Muzzarelli RAA. Potential of chitin/chitosan-bearing materials for uranium recovery: an interdisciplinary review. Carbohydr Polym 2011;84:54-63.

[6] Reddy DHK, Lee S-M. Application of magnetic chitosan composites for the removal of toxic metal and dyes from aqueous solutions, Adv Colloid Interface Sci 2013;201-202:68-93.

[7] Singh J, Srivastava M, Kalita P, Malhotra BD. A novel ternary $\mathrm{NiFe}_{2} \mathrm{O}_{4} / \mathrm{CuO} / \mathrm{FeO}$-chitosan nanocomposite as a cholesterol biosensor. Process Biochem 2012;47:2189-98.

[8] Luo L, Li Q, Xu Y, Ding Y, Wang X, Deng D, Xu Y. Amperometric glucose biosensor based on $\mathrm{NiFe}_{2} \mathrm{O}_{4}$ nanoparticles and chitosan. Sens Actuators B 2010;145:293-8.

[9] Lin Y, Yao W, Cheng Y, Qian H, Wang X, Ding Y, Wu W, Jiang X. Multifold enhanced T2 relaxation of $\mathrm{ZnFe}_{2} \mathrm{O}_{4}$ nanoparticles by jamming them inside chitosan nanospheres. J Mater Chem 2012;22:5684-93.

[10] Guo YH, Li FR, Bao SY, Han T, Cao JJ, Zhou HX. Preparation and characteristics of carboplatin-Fe@Cloaded chitosan nanoparticles with dual physical drug-loaded mechanisms. Curr Appl Phys 2007;7:e97-e102. 
[11] Yang PF, Lee CK. Hyaluronic acid interaction with chitosan-conjugated magnetite particles and its purification. Biochem Eng J 2007;33:284-289.

[12] Sobhani A, Salavati-Niasari M, Hosseinpour-Mashkani SM. Single-source molecular precursor for synthesis of copper sulfide nanostructures. J Clust Sci 2012;23:1143-1151.

[13] Esmaeili-Zare M, Salavati-Niasari M, Sobhani A. Simple sonochemical synthesis and characterization of HgSe nanoparticles. Ultrason Sonochem 2012;19:1079-1086.

[14] Sobhani A, Salavati-Niasari M. Sodium dodecyl benzene sulfonate-assisted synthesis through a hydrothermal reaction. Mater Res Bull 2012;47:1905-1911.

[15] Salavati-Niasari M, Esmaeili-Zare M, Sobhani A. Synthesis and characterization of cadmium selenide nanostructures by simple sonochemical method. Micro Nano Lett 2012;7:831-834.

[16] Salavati-Niasari M, Sobhani A. Effect of nickel salt precursors on morphology, size, optical property and type of products (NiSe or Se) in hydrothermal method. Opt Mater 2013;35:904-909.

[17] Ansari F, Sobhani A, Salavati-Niasari M. Sol-gel auto-combustion synthesis of $\mathrm{PbFe}_{12} \mathrm{O}_{19}$ using maltose as a novel reductant. RSC Adv 2014;4:63946-63950.

[18] Qin R, Li F, Jiang W, Chen M. Synthesis and characterization of diethylenetriaminepentaacetic acid-chitosancoated cobalt ferrite core/shell nanostructures. Mater Chem Phys 2010;122:498-501.

[19] Zhu HY, Jiang R, Xiao L, Zeng GM. Preparation, characterization, adsorption kinetics and thermodynamics of novel magnetic chitosan enwrapping nanosized $\gamma-\mathrm{Fe}_{2} \mathrm{O}_{3}$ and multi-walled carbon nanotubes with enhanced adsorption properties for methyl orange. Bioresour Technol 2010;101:5063-9.

[20] Covaliu CI, Berger D, Matei C, Diamandescu L, Vasile E, Cristea C, Ionita V, Iovu H. Magnetic nanoparticles coated with polysaccharide polymers for potential biomedical applications. J Nanopart Res 2011;13:6169-6180.

[21] Ramimoghadam D, Bagheri S, Termeh Yousefi A, Bee Abd Hamid S. Statistical optimization of effective parameters on saturation magnetization of nanomagnetite particles. J Magn Magn Mater 2015;393:30-35. 
[22] Ramimoghadam D, Bagheri S, Bee Abd Hamid S. In-situ precipitation of ultra-stable nano-magnetite slurry. J Magn Magn Mater 2015;379:74-79.

[23] Ramimoghadam D, Bagheri S, Bee Abd Hamid S. Stable monodisperse nanomagnetic colloidal suspensions: An overview. Colloids Surf B 2015;133:388-411.

[24] Ramimoghadam D, Bagheri S, Bee Abd Hamid S. Progress in electrochemical synthesis of magnetic iron oxide nanoparticles. J Magn Magn Mater 2014;368:207-229.

[25] Kim H, Achermann M, Baer LP, Hollingsworth JA, Llimov VI. Synthesis and characterization of Co/CdSe core/shell nanocomposites: Bifunctional magnetic-optical nanocrystals. J Am Chem Soc 2005;127:544-546.

[26] Akbar S, Hasanain SK, Azmat N, Nadeem M. Synthesis of $\mathrm{Fe}_{2} \mathrm{O}_{3}$ nanoparticles by new sol-gel method and their structural and magnetic characterizations. J Appl Sci Res 2008;3:417-433.

[27] Qin R, Li F, Jiang W, Chen M. Synthesis and characterization of diethylenetriaminepentaacetic acid-chitosancoated cobalt ferrite core/shell nanostructures. Mater Chem Phys 2010;122:498-501. 


\section{Figure captions}

Fig. 1. SEM images of samples prepared: (a, b) without onion (sample no. 1) , (c, d) with 20 ml onion (sample no.

2), (e, f) with $40 \mathrm{ml}$ onion (sample no. 3).

Fig. 2. SEM images of the nanocomposites prepared in the presence of different amounts of chitosan: (a) $\% 0.5$,

(b) $\% 1$, , (c) $\% 2$, (d) $\% 5$ (e) $\% 10$, (f) $\% 50$.

Fig. 3. TEM images of samples prepared with $40 \mathrm{ml}$ onion (a) without chitosan , (b, c) with $1 \%$ chitosan.

Fig. 4. XRD patterns of samples prepared with $40 \mathrm{ml}$ onion (a) without chitosan , (b) with $1 \%$ chitosan.

Fig. 5. FT-IR spectra of: (a) sample no. 3 , (b) sample no. 5.

Fig. 6. $\mathrm{M}-\mathrm{H}$ hysteresis at $300 \mathrm{~K}$ for sample no. 3 and sample no. 5.

Table 1. The reaction conditions of the nanocomposites synthesized in this work.

Table 2. Comparison of magnetic hysteresis parameters of two samples no. 3 and 5. 
Table 1.

\begin{tabular}{|c|c|c|c|c|c|c|c|}
\hline Sample no. & Fe Source & Cu Source & $\mathrm{Cu}: \mathrm{Fe}$ & Onion (ml) & $\begin{array}{c}\text { Temperature } \\
\left({ }^{\circ} \mathrm{C}\right)\end{array}$ & $\begin{array}{l}\text { Time } \\
\text { (h) }\end{array}$ & $\begin{array}{l}\text { Chitosan } \\
(\% \mathrm{~W} / \mathrm{W})\end{array}$ \\
\hline 1 & $\mathrm{Fe}\left(\mathrm{NO}_{3}\right)_{3} .9 \mathrm{H}_{2} \mathrm{O}$ & $\mathrm{Cu}\left(\mathrm{NO}_{3}\right)_{2}$ & $1: 12$ & - & 900 & 3 & - \\
\hline 2 & $\mathrm{Fe}\left(\mathrm{NO}_{3}\right)_{3} \cdot 9 \mathrm{H}_{2} \mathrm{O}$ & $\mathrm{Cu}\left(\mathrm{NO}_{3}\right)_{2}$ & $1: 12$ & 20 & 900 & 3 & - \\
\hline 3 & $\mathrm{Fe}\left(\mathrm{NO}_{3}\right)_{3} \cdot 9 \mathrm{H}_{2} \mathrm{O}$ & $\mathrm{Cu}\left(\mathrm{NO}_{3}\right)_{2}$ & $1: 12$ & 40 & 900 & 3 & - \\
\hline 4 & $\mathrm{Fe}\left(\mathrm{NO}_{3}\right)_{3} .9 \mathrm{H}_{2} \mathrm{O}$ & $\mathrm{Cu}\left(\mathrm{NO}_{3}\right)_{2}$ & $1: 12$ & 40 & 900 & 3 & 0.5 \\
\hline 5 & $\mathrm{Fe}\left(\mathrm{NO}_{3}\right)_{3} \cdot 9 \mathrm{H}_{2} \mathrm{O}$ & $\mathrm{Cu}\left(\mathrm{NO}_{3}\right)_{2}$ & $1: 12$ & 40 & 900 & 3 & 1 \\
\hline 6 & $\mathrm{Fe}\left(\mathrm{NO}_{3}\right)_{3} \cdot 9 \mathrm{H}_{2} \mathrm{O}$ & $\mathrm{Cu}\left(\mathrm{NO}_{3}\right)_{2}$ & $1: 12$ & 40 & 900 & 3 & 2 \\
\hline 7 & $\mathrm{Fe}\left(\mathrm{NO}_{3}\right)_{3} .9 \mathrm{H}_{2} \mathrm{O}$ & $\mathrm{Cu}\left(\mathrm{NO}_{3}\right)_{2}$ & $1: 12$ & 40 & 900 & 3 & 5 \\
\hline 8 & $\mathrm{Fe}\left(\mathrm{NO}_{3}\right)_{3} .9 \mathrm{H}_{2} \mathrm{O}$ & $\mathrm{Cu}\left(\mathrm{NO}_{3}\right)_{2}$ & $1: 12$ & 40 & 900 & 3 & 10 \\
\hline 9 & $\mathrm{Fe}\left(\mathrm{NO}_{3}\right)_{3} \cdot 9 \mathrm{H}_{2} \mathrm{O}$ & $\mathrm{Cu}\left(\mathrm{NO}_{3}\right)_{2}$ & $1: 12$ & 40 & 900 & 3 & 50 \\
\hline
\end{tabular}


Table 2.

\begin{tabular}{ccccc}
\hline Sample no. & Product & $\mathrm{M}_{\mathrm{r}}(\mathrm{emu} / \mathrm{g})$ & $\mathrm{M}_{\mathrm{s}}(\mathrm{emu} / \mathrm{g})$ & $\mathrm{H}_{\mathrm{c}}(\mathrm{Oe})$ \\
\hline 3 & $\mathrm{CuFe}_{12} \mathrm{O}_{19}$ & 6.98 & 12.19 & 683 \\
5 & $\mathrm{CuFe}_{12} \mathrm{O}_{19} /$ chitosan & 3.25 & 9.49 & 135 \\
\hline
\end{tabular}



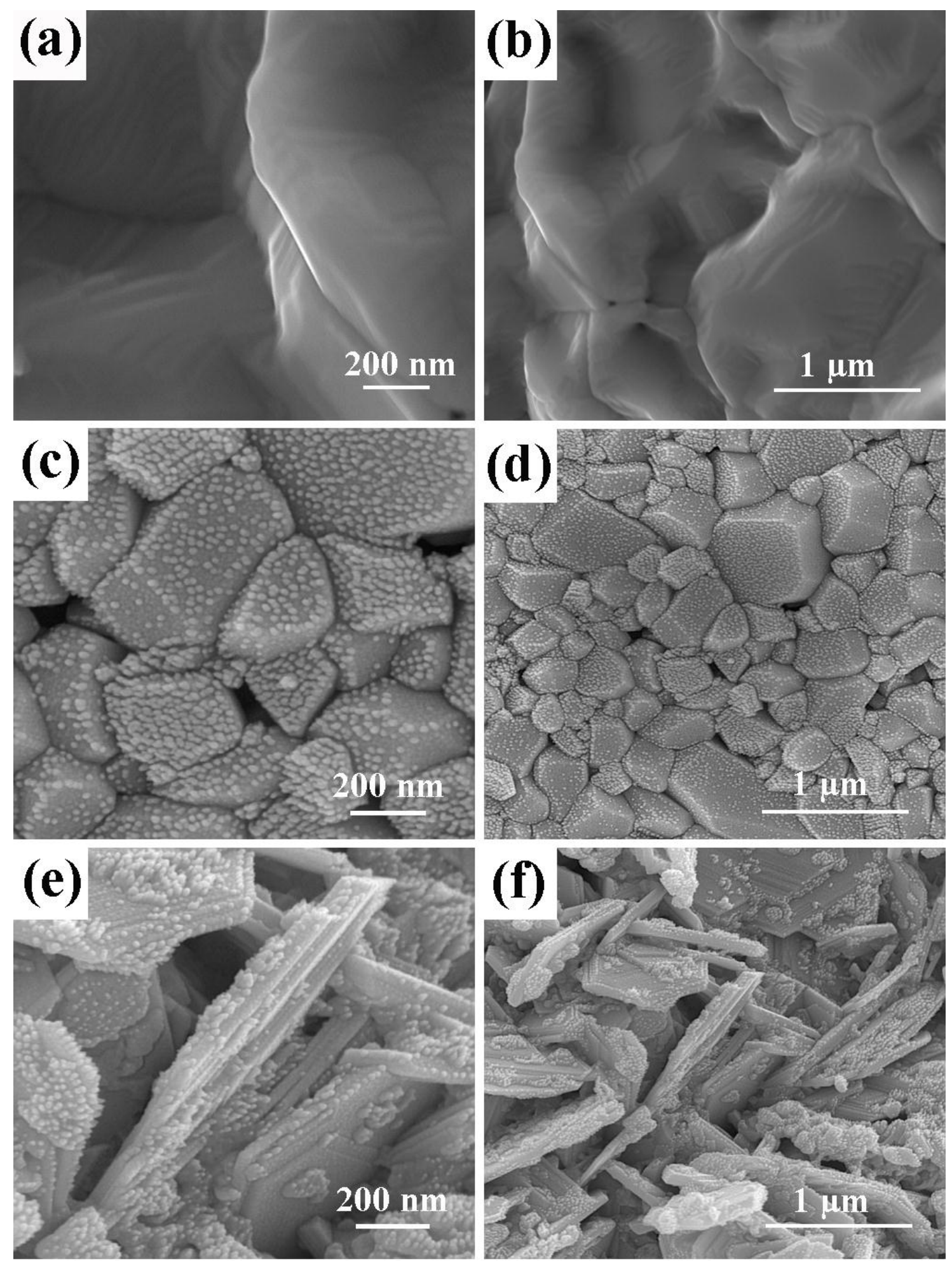

Fig. 1. 

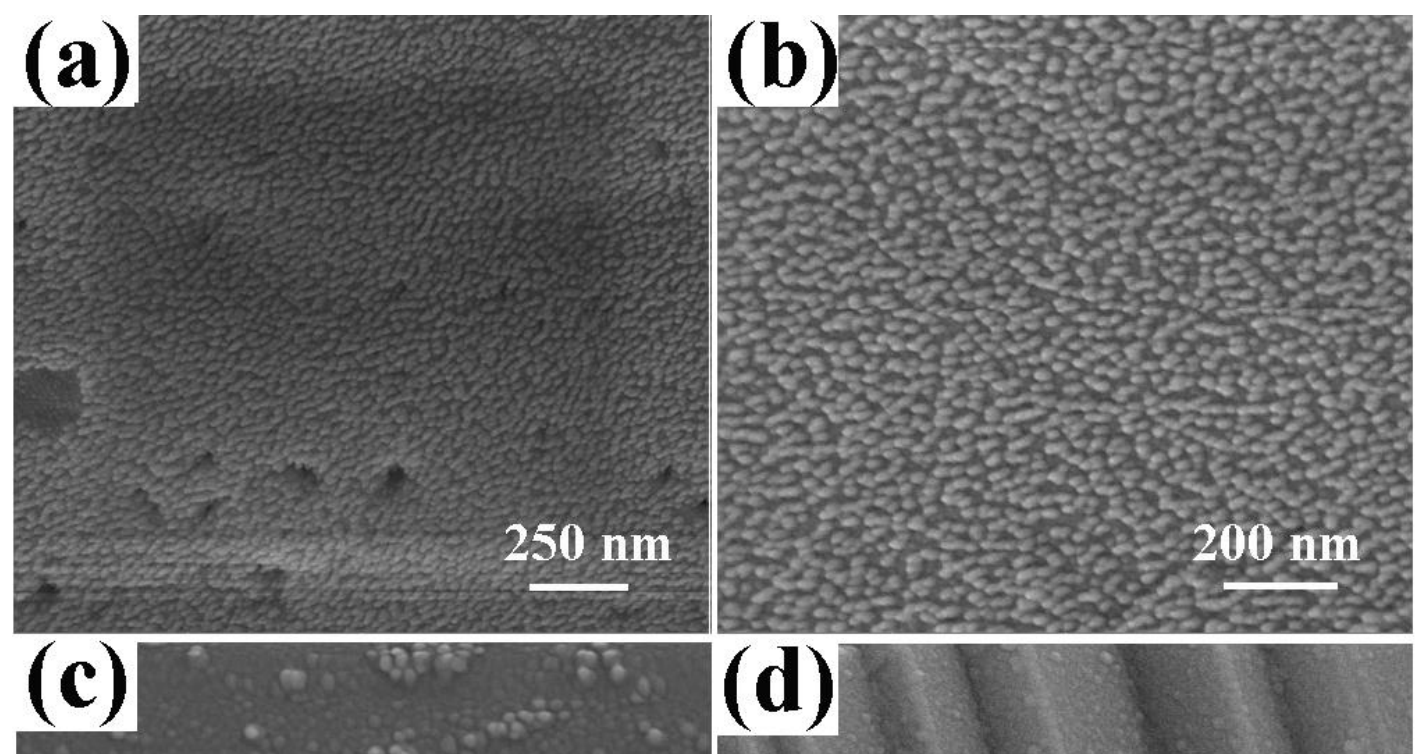

(d)
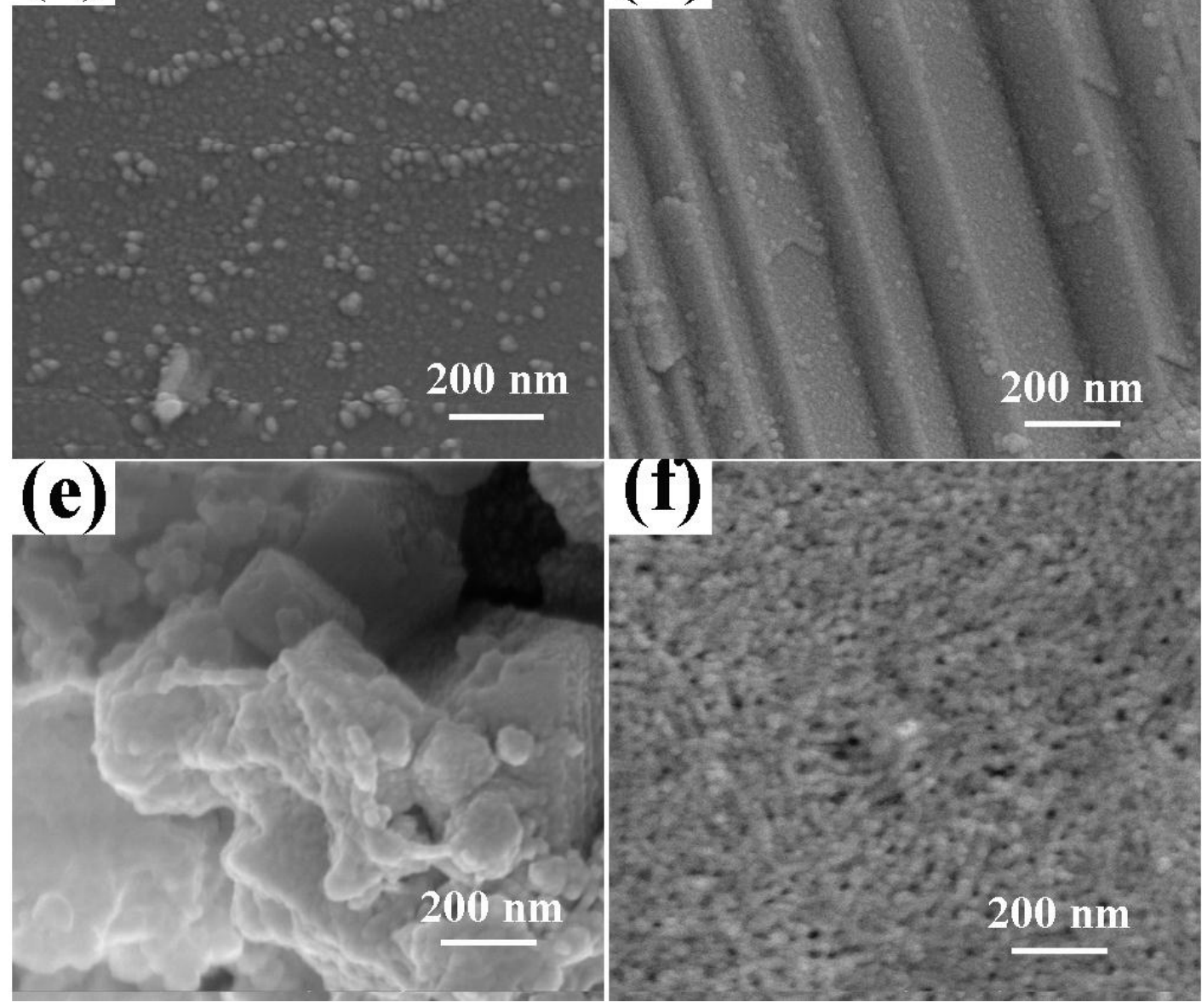

Fig. 2. 


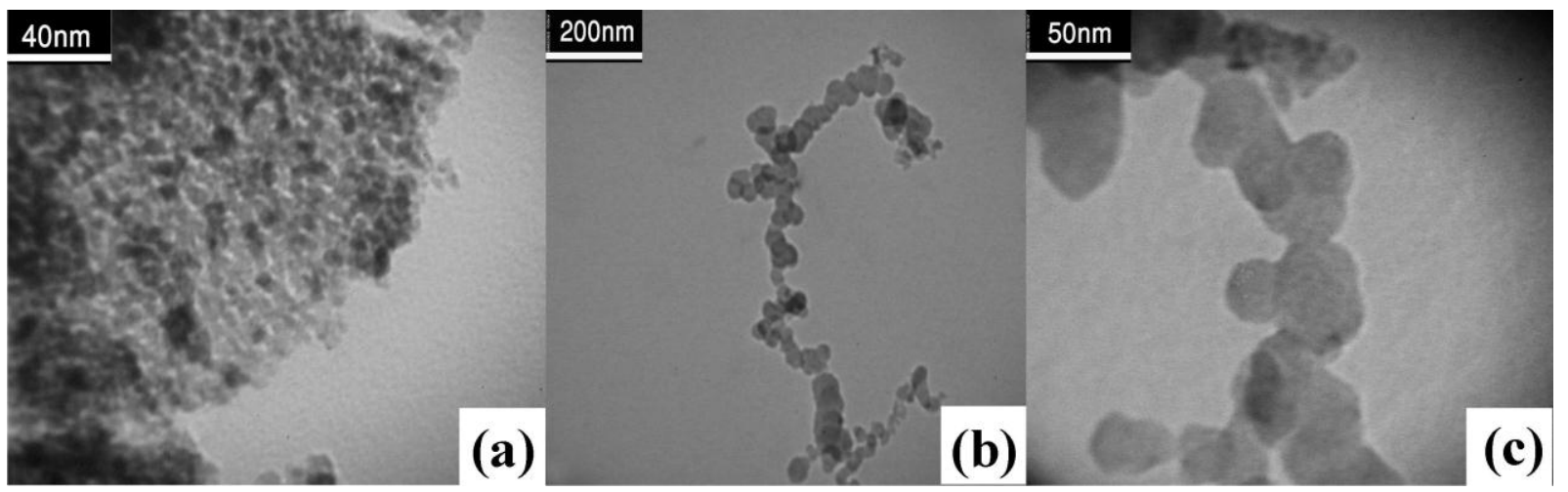

Fig. 3. 


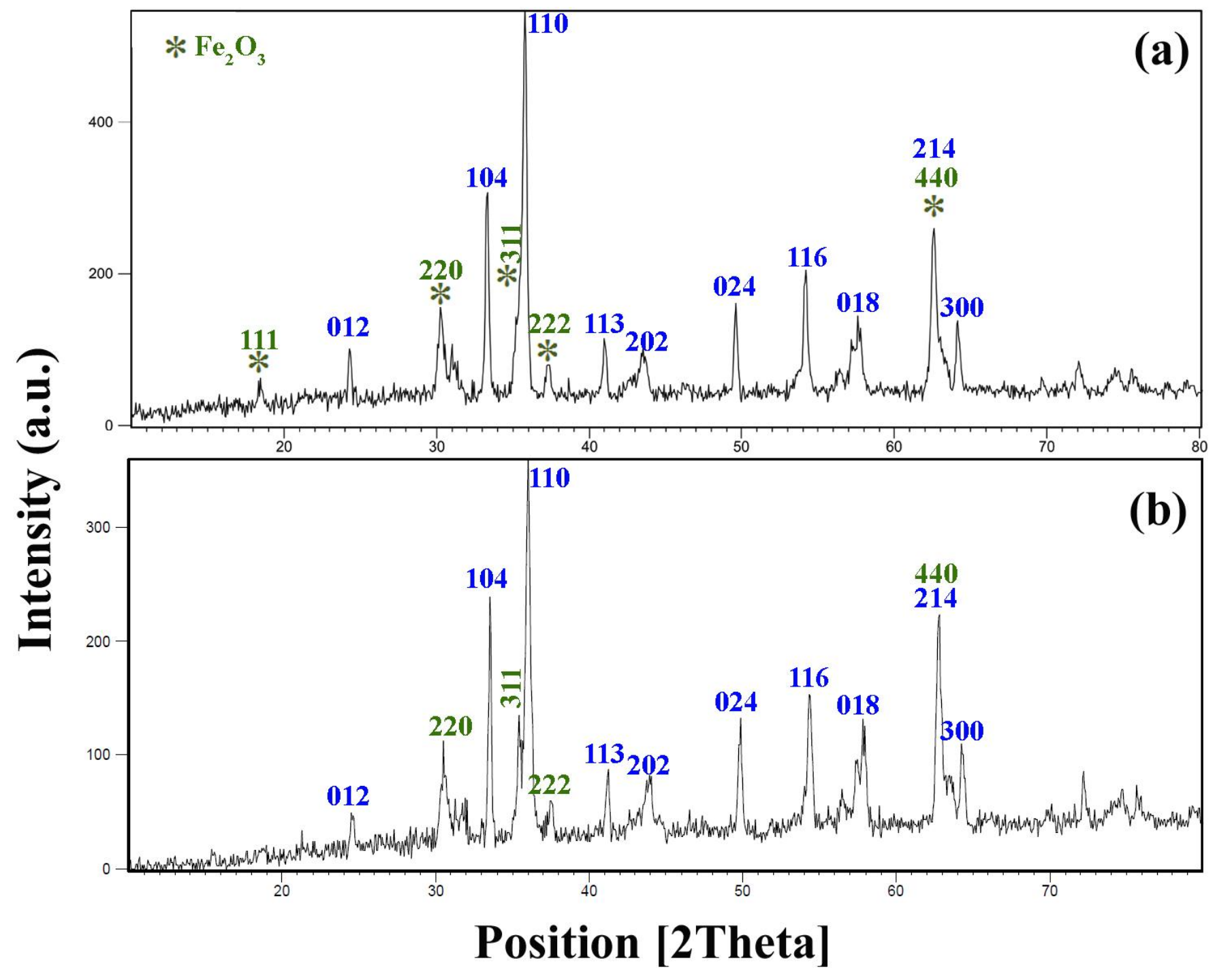

Fig. 4. 


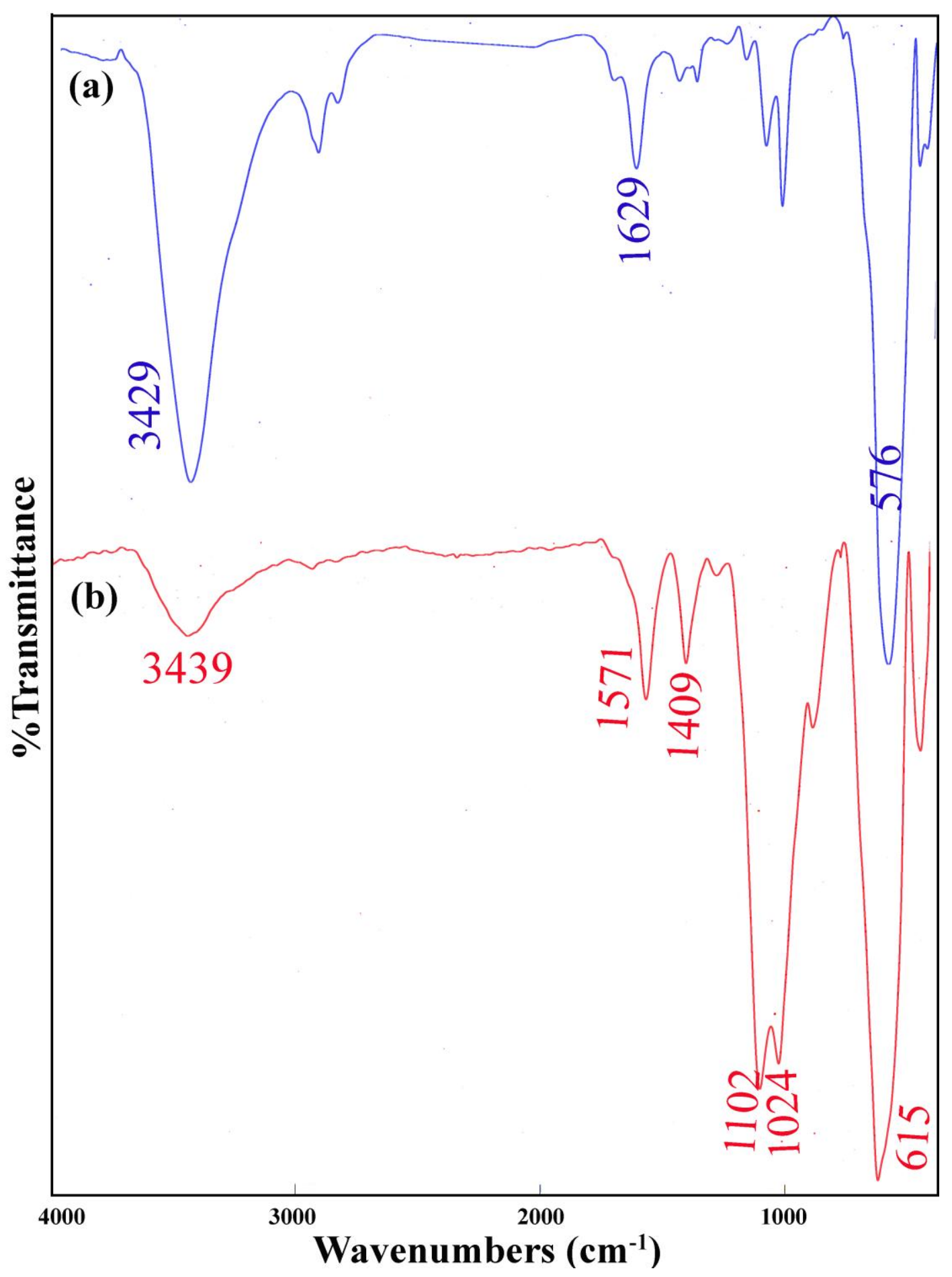

Fig. 5. 


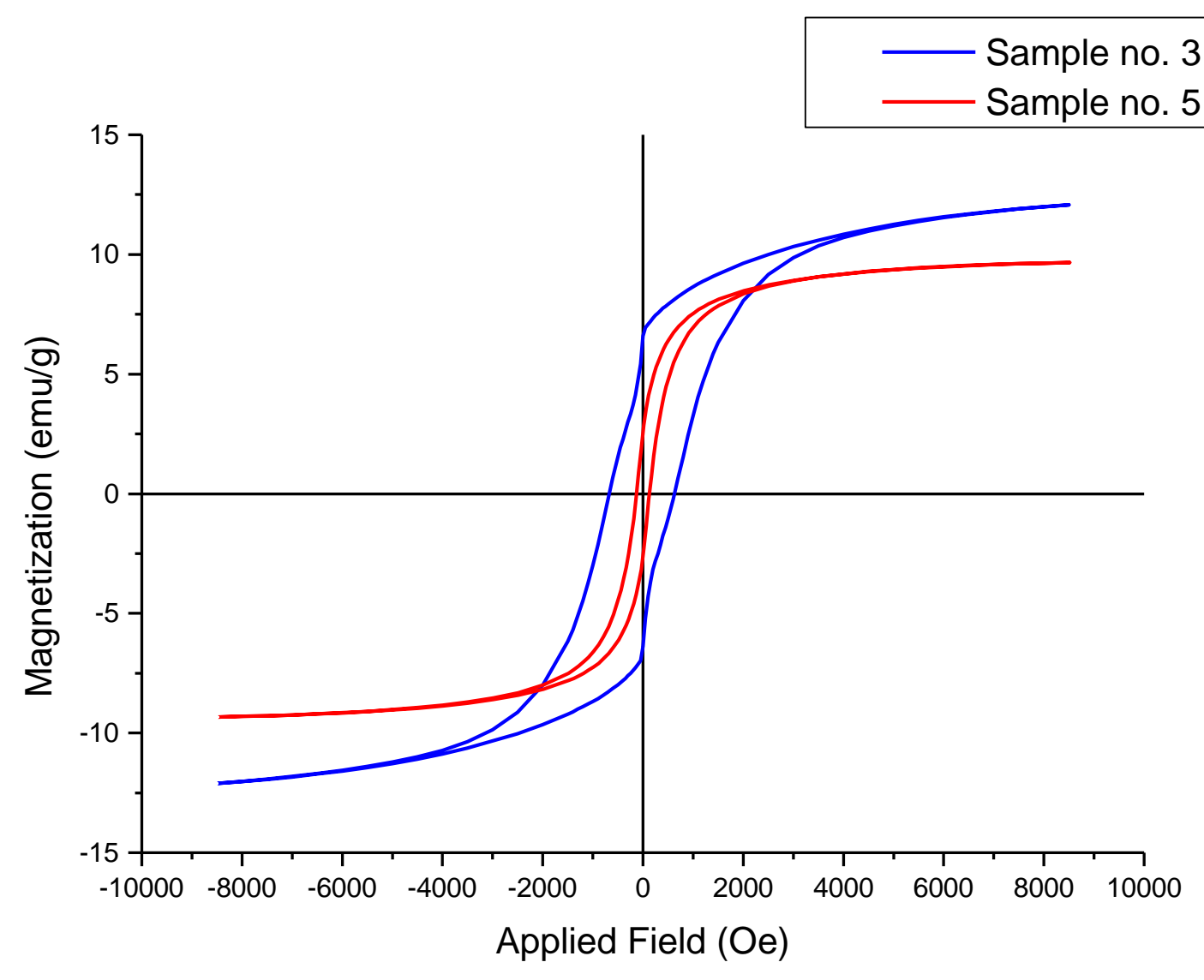

Fig. 6. 


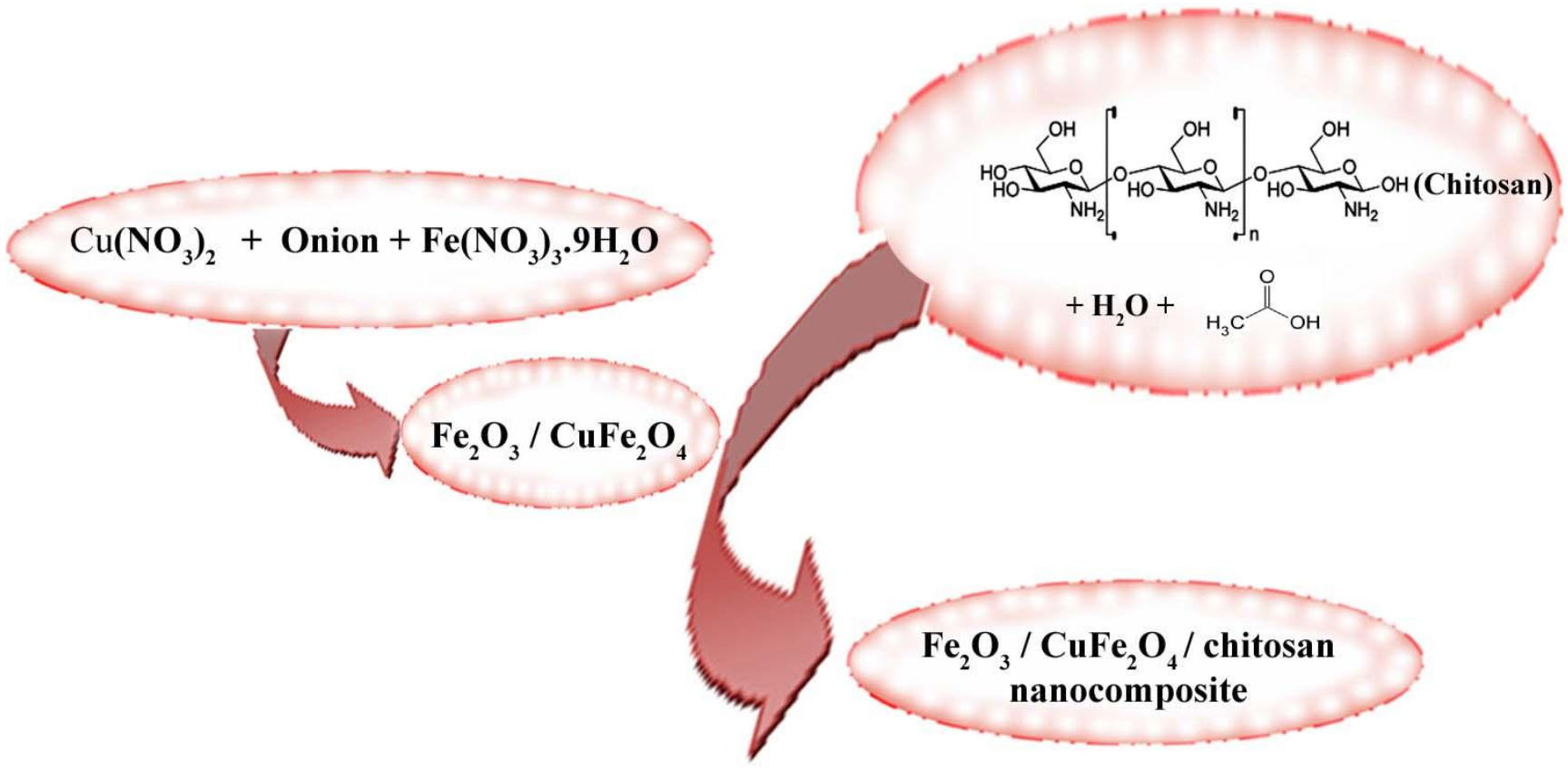

